\title{
Percepção do Acidente Fatal de Trabalho para a Família da Vítima
}

\author{
Perception Of The Fatal Work \\ Accident For The Victim's Family \\ Percepción Del Accidente Fatal
} De Trabajo Para La Familia De La Víctima
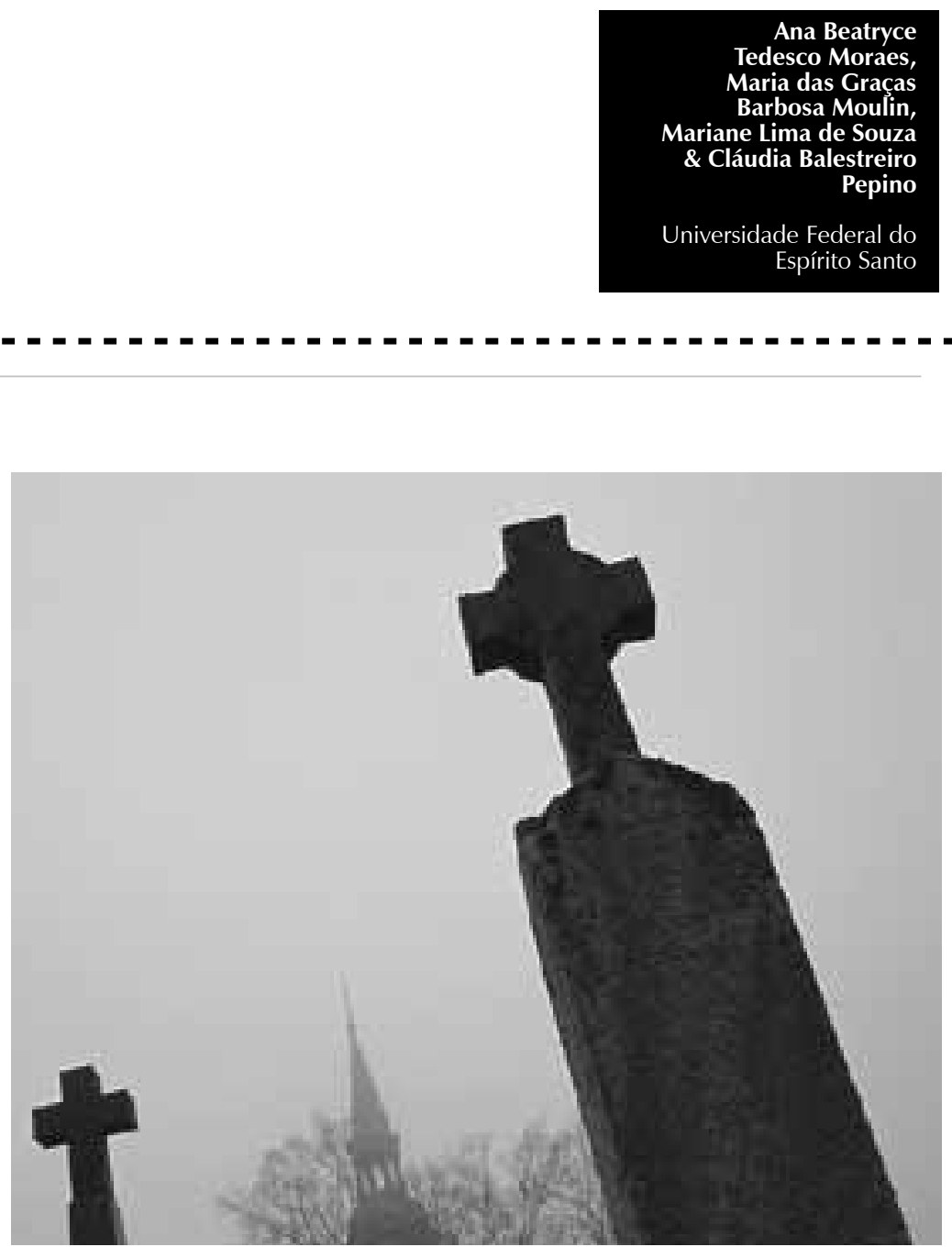
Resumo: O trabalho humano constitui importante meio de inserção social, implicado na formação de identidade e de reconhecimento social. Em caso de acidente de trabalho fatal, a família sofre os impactos desse fenômeno em sua organização e dinâmica. Esta pesquisa teve por objetivo investigar a percepção do acidente de trabalho fatal para a família de uma vítima no sul do Estado do Espírito Santo, cuja análise se baseou nos seguintes temas: condições de trabalho do acidentado, impactos psicossociais gerados pelo acidente de trabalho e mudanças na dinâmica familiar em função dessa ocorrência. Foram entrevistados três membros da família da vítima e seu empregador. Os dados foram analisados conforme os critérios qualitativos da fenomenologia semiótica. Os resultados apontam um paradoxo na percepção da família da vítima e do empregador sobre o acidente: enquanto sua repercussão para a família se fundamenta na importância social do trabalho, para o empregador, associa-se à defesa da empresa e de sua responsabilidade sobre a morte no trabalho.

Palavras-chave: Acidentes de trabalho. Morte. Percepção. Fatores psicossociais.

Abstract: Human work is an important means of social insertion, implied in the formation of the identity and social acknowledgement. In the case of a fatal work accident, the family suffers the impacts of that phenomenon in its organization and dynamic. The work aimed at investigating the perception of a fatal work accident for the family of a victim in the south of Espírito Santo, whose analysis was based on the following themes: the working conditions of the one who had the accident, the psychosocial impacts created by the work accident and the changes in the familial dynamic due to such occurrence. Three members of the victim's family and his/her employer were interviewed. Data were analyzed according to the qualitative criteria of the semiotic phenomenology. Results indicate a paradox in the victim's family and in the employer's perception of the accident: while its repercussion for the family is based on the social importance of work, for the employer, it is associated to the company's defense and its responsibility regarding the death held at work. Keywords: Work accidents. Death. Perception. Psychosocial factors.

Resumen: El trabajo humano constituye un importante medio de inserción social, implicado en la formación de identidad y de reconocimiento social. En caso de un accidente de trabajo fatal, la familia sufre los impactos de ese fenómeno en su organización y dinámica. Esta investigación tuvo por objetivo estudiar la percepción del accidente de trabajo fatal para la familia de una víctima en el sur del Estado de Espírito Santo, cuyo análisis se basó en los siguientes temas: condiciones de trabajo del accidentado, impactos psicosociales generados por el accidente de trabajo y cambios en la dinámica familiar en función de ese suceso. Fueron entrevistados tres miembros de la familia de la víctima y su empleador. Los datos fueron analizados de acuerdo a los criterios cualitativos de la fenomenología semiótica. Los resultados apuntan una paradoja en la percepción de la familia de la víctima y del empleador sobre el accidente: mientras su repercusión para la familia se fundamenta en la importancia social del trabajo, para el empleador, se asocia a la defensa de la empresa y de su responsabilidad sobre la muerte en el trabajo.

Palabras clave: Accidentes de trabajo. Muerte. Percepción. Factores psicosociales.

O trabalho é um importante meio de inserção social em nossa sociedade, relacionado tanto com a subsistência material quanto com as questões sociais e culturais, como identidade e reconhecimento (Dejours, Abdoucheli, \&

(1) Projeto realizado sob a coordenação da Dra. e professora Maria das Graças Barbosa Moulin e participação das alunas Martha Helena Raizem (bolsista pela FAPES), Laize Dalla Bernardina Monteiro e Ana Beatryce Tedesco Moraes. Jayet, 2009; Jardim, 2001). As implicações psicológicas da organização do trabalho, bem como sua repercussão nas relações familiares, têm sido objeto de interesse de alguns estudos (Seligmann-Silva, 1990; Matsuo, 2002), inclusive associados aos acidentes de trabalho (Nardi, 1998; Moulin, 2007; Mangas, MinayoGomez, \& Thedim-Costa, 2008).

Em pesquisa realizada no sul do Espírito
Santo, Moulin (2010) retrata os impactos sociais gerados por acidentes de trabalho fatais no setor de rochas ornamentais, como alterações na organização familiar em função da perda do provedor da família, agravos à saúde e dificuldades financeiras e na educação dos filhos. Mangas et al. (2008) relataram os impactos sociais nas famílias de vítimas de acidentes de trabalho fatais na indústria da construção civil, destacando o desamparo social e legal, o uso de medicamentos pelos familiares e dificuldades relativas às necessidades básicas. Nesses estudos, os autores observaram que os familiares do acidentado contam com a ajuda da família ampliada, de vizinhos e da religião. 
A indústria do mármore destaca-se, no Estado do Espírito Santo, pelo crescimento econômico e pela geração de empregos, além de ser responsável pela manutenção de uma dinâmica social pautada na relação entre trabalho, comunidade e religião, como revelou Moulin (2008). Para a autora, o trabalho viabiliza a aquisição de atributos que são considerados positivos pelo trabalhador e que também são valorizados pela família e pela comunidade. Essa valorização, por sua vez, contribui para a naturalização dos acidentes, em que a morte é entendida como fatalidade. Se, por um lado, a religião traz elementos que sustentam essa naturalização, por outro, é importante para a superação e o enfrentamento das mortes por acidente de trabalho.

O objetivo do presente estudo foi investigar a percepção de um acidente de trabalho fatal no setor de rochas ornamentais para uma família do sul do Espírito Santo. Buscou-se, neste artigo, discutir aspectos psicossociais do acidente de trabalho ressaltando a percepção dos familiares sobre esse fato, bem como as percepções do empregador. O acidente de trabalho (fatal ou não) implica mudanças na configuração familiar, revelando a importância do estudo qualitativo sobre a percepção da família e da empresa sob a perspectiva vivencial desse fenômeno. A pesquisa foi pautada na abordagem metodológica da fenomenologia semiótica.

Os depoimentos dos informantes foram analisados de acordo com os critérios da pesquisa qualitativa, utilizando-se a metodologia da fenomenologia-semiótica (Gomes, 1998; Lanigan, 1997). Tal método permitiu a exploração da perspectiva experiencial do acidente de trabalho segundo os familiares da vítima e o empregador; visa, então, a compreender a descrição que os informantes oferecem da situação, do modo como vivenciaram o fenômeno do acidente fatal.
Método

\section{Participantes}

Foram entrevistados três membros da família de uma vítima de acidente de trabalho fatal no setor de rochas ornamentais: a mãe, o pai e a cunhada. Entrevistou-se também o empregador, proprietário da empresa de beneficiamento de mármore e granito na qual o acidentado trabalhava. O contato com os informantes foi viabilizado pelo Projeto de Iniciação Científica: Levantamento de acidentes fatais ocorridos em 2008 no setor de rochas ornamentais no Estado do Espírito Santo (Moulin \& Raizem, 2010), do Curso de Psicologia da Universidade Federal do Espírito Santo (1), que recebeu apoio do Sindicato dos Trabalhadores em Indústria de Extração e Beneficiamento do Mármore, Granito e Calcário do Espírito Santo (SINDIMÁRMORE). Um membro do sindicato também forneceu informações sobre o acidente em conversa informal.

\section{Instrumento / procedimento}

Utilizou-se a entrevista semiestruturada, caracterizada como uma conversa, mas com propósitos bem definidos pelo pesquisador, como forma de obter informações construídas no diálogo com os informantes (Minayo, 2007). A escolha por esse tipo de entrevista fundamenta-se na pesquisa fenomenológica, que propõe essa forma como facilitadora da emergência dos itens previstos no roteiro (Magalhães, Lassance, \& Gomes, 1998).

As anotações em diário de campo sobre as observações e as impressões dos pesquisadores e as informações fornecidas pelo Sindicato e pela Comunicação de Acidente de Trabalho (CAT) auxiliaram na análise das entrevistas. A CAT é um registro obrigatório, sob o ponto de vista legal, que reconhece oficialmente o acidente (Wunsch-Filho, 1999) e contém diversas informações sobre o acidente e a vítima. 


\section{Critérios de interpretação e validação}

A metodologia da fenomenologia-semiótica caracteriza-se por uma análise e síntese que atende ao critério de suspensão das pressuposições dos pesquisadores. Na prática, o método fenomenológico evidencia-se por um processo progressivo, sistêmico e sistemático de passos reflexivos: descrição, redução e interpretação. É importante ressaltar que cada passo está contido no outro como totalidade (Gomes, 1998).

O primeiro passo consistiu em descrever a percepção dos membros da família e do empregador sobre o acidente, que se caracteriza como redução e interpretação devido ao recorte que o pesquisador faz de suas escolhas dos elementos essenciais da narrativa dos participantes. Compreende-se o fenômeno do ponto de vista dos entrevistados, adotando-se cuidado e rigor para minimizar o seu viés interpretativo. Assim, descreve-se o acidente segundo as narrativas dos informantes; a descrição, contudo, é uma construção do pesquisador que delineou os temas e que os apresenta em forma de narrativa sustentada por exemplos por ele selecionados.

O passo seguinte foi a redução a aspectos e temas significativos nas narrativas dos informantes. A recorrência de alguns elementos facilita a redução fenomenológica: os relatos são reduzidos aos componentes essenciais.

O último passo, a interpretação, é momento em que se discutem as categorias selecionadas na fase anterior. A direcionalidade adotada no passo anterior será explicitada na interpretação. Dessa forma, buscou-se evidenciar o significado do que se determinou como essencial na descrição da experiência dos participantes que foi investigada.

\section{Resultados e discussão Descrição fenomenológica}

\section{A vítima e o acidente}

Antes de descrever a experiência dos participantes em relação ao fenômeno investigado (acidente de trabalho fatal), foram apresentados os dados demográficos da vítima e um breve histórico do acidente de trabalho, tomando como fonte as informações contidas na CAT. De acordo com esse documento, o trabalhador tinha 22 anos, era solteiro, possuía ensino fundamental incompleto e sua função era servente de obras. Os informantes relataram que a vítima tinha três irmãos e três irmãs, não tinha filhos, morava com os pais e ajudava nas despesas de casa.

A CAT revela ainda que o acidente ocorreu em 2007, em uma empresa de beneficiamento de mármore e granito, após uma jornada de trabalho de oito horas e dez minutos, às três horas e dez minutos da madrugada, no tear da empresa. Houve aprisionamento por mineral não metálico (chapas de granito), com fratura da base do crânio (inclusive encéfalo).

\section{Condições de trabalho}

As percepções dos familiares a respeito das causas do acidente referem-se ao contexto e às condições de trabalho da atividade realizada pela vítima, como o pouco tempo de experiência no trabalho, o tipo de vínculo estabelecido com a empresa e a demora no socorro da vítima. Conforme relato do pai:

Diz que, na hora (do acidente), eles tiraram o ajudante que ajudava ele pra ir fazer outro serviço e largaram ele sozinho, meia-noite. Aí, quando foi de madrugada, aconteceu esse desastre com ele. Largaram ele sozinho. O menino não tinha experiência, estava trabalhando ainda sem experiência.

Outra condição de trabalho desfavorável evidenciada pelos familiares foi o tipo de vínculo 
empregatício estabelecido entre a vítima e a empresa, no qual inexistia contrato formal. De acordo com os informantes, a carteira de trabalho só foi assinada após o acidente: “(...) Eles só assinaram a carteira dele depois que ele morreu. No dia que ele morreu, enrolaram ainda para entregar a carteira dele. Aí eles assinaram correndo para entregar a carteira para dizer que ele tava de carteira assinada" (cunhada).

Os familiares afirmam não ter informações precisas sobre o acidente e relatam que um colega de trabalho presenciou o evento, mas recusou-se a descrevê-lo em detalhes, acreditam que por medo de perder o emprego. Esclarecem, ainda, que, quando o acidente aconteceu, eles foram impedidos de entrar na pedreira, e a vítima ficou presa entre as pedras por três horas até ser socorrida:

Ele trabalhava numa prensa lá, que entrava (...) de banda, porque ele não podia virar que não dava pra passar virado. la lá no fundo como daqui lá na porta assim, ó. ... E ele tava no meio das pedras assim (fez gesto com as duas mãos, como o telhado de uma casa). Aí deu que ele tinha que mexer num canto lá, não sabe como é que foi que a pedra veio e bateu na cabeça. Morreu em pé assim, ó, morreu em pezinho assim, sem poder virar (pai).

Para o pai, o fato de o filho não ter sido socorrido impossibilitou saber os motivos do acidente, e, então, a culpa recaiu sobre o filho:

Creio que o homem não deixou ir ninguém lá ver ele, não deixou chamar polícia pra ver como é que tava, não deixou ninguém tirar. Os empregados quiseram chamar a polícia pra abrir e ele não deixou. Ninguém, ninguém viu como é que foi a morte do menino. Uma coisa triste. Ele ficou como criminoso, nesse ponto (pai).

O empregador explica que impediu a entrada na pedreira após o acidente para que não houvesse modificação do local e dos fatos, pois, devido a sua experiência no ramo, sabe que a empresa poderia ser culpabilizada pela morte do funcionário, se isso acontecesse. Ele não ofereceu informações esclarecedoras sobre a forma como o acidente aconteceu, mas relatou que o funcionário foi tirar o calço das chapas de um lado e passou por entre elas para retirar o calço do outro lado, quando foi imprensado pelas chapas. A percepção do acidente de trabalho para o empregador relaciona-se com a negligência do funcionário, já que ele havia sido treinado e sabia que não podia passar entre as chapas.

Conforme informações do SINDIMÁRMORE, para o funcionário realizar essa atividade de retirar as chapas no tear, precisa, necessariamente, passar entre as chapas, pois não há outro modo de executar o trabalho. As normas preveem uma forma de trabalho que, na prática, não é possível de ser realizada. A família levanta a suspeita de falta de segurança na atividade que a vítima exercia, conforme destaca a cunhada: "Eu acho que assim, deve tá faltando algum equipamento. Porque igual meu marido falou que faltava 'L' (tipo de calço) nas pernas para poder segurar, porque, se tivesse os 'L', não tinha imprensado ele".

O empregador, explicando seu empenho em prevenir acidentes, relatou que realiza treinamentos, registros de ocorrências, registros de atuação da CIPA e possui dois técnicos de segurança do trabalho, um apenas para tratar da burocracia pertinente à legislação e outro responsável pela fiscalização. Este último não avisa o horário de trabalho com o objetivo de "pegar o funcionário no flagra", pois entende que os funcionários só realizam as atividades conforme o padrão de segurança na presença do técnico. Na perspectiva do empregador, o investimento em segurança do trabalho e o histórico da empresa não são levados em consideração ao se investigar o acidente:

Na Justiça comum, você é inocente até que se prove o contrário; na empresa, você é culpado até que se prove o contrário para o Ministério Público e Ministério do Trabalho. Se, na Justiça comum é levado em consideração os antecedentes, no julgamento da empresa, não (empregador). 


\section{Consequências psicossociais}

Os três membros da família relatam sentimentos de tristeza. A mãe não conseguiu dar entrevista, ficando sua fala restrita quase exclusivamente à dificuldade de falar na morte do filho. $\mathrm{A}$ cunhada menciona sentimento de perda e vazio dentro de casa e comenta ainda sobre alguns comportamentos do marido após a morte do irmão, como o fato de chorar ao se lembrar do acidente e preferir não falar no assunto. O pai, referindo-se aos outros filhos, relata que eles "(...) ficaram muito triste, né? Fazer o quê? Se conformar, não tinha outro jeito, né? Não podia ficar bravo, saber que morreu, morreu".

De acordo com a informante, todos os familiares foram impactados de alguma forma pela morte do cunhado, inclusive nos momentos de comemoração em família: "Aí ficou aquele sentimento, aquele vazio, né? Sentimento de perda, aquela coisa assim tanto pra ele quanto pra mim, meu marido, irmão, tudo, principalmente pra mãe dele, porque é aniversário, é Natal, é tudo lembra dele, tudo" (cunhada).

A mãe ressalta que não tem condições de falar sobre o acidente do filho, porque é muito doloroso: "A minha vida hoje tá cada vez mais sofrida. (...) Mas é assim, vai levando essa vida aí, de sofrimento aí... Não tem como esquecer. Não esqueço, não tem jeito. Tem dois anos, mas pra mim parece que aconteceu ontem". A cunhada relata grande preocupação com o marido após o acidente, e conta que ele trabalhava na mesma empresa junto com o irmão e foi demitido alguns meses depois do acidente, mas continua trabalhando no setor de rochas ornamentais:

Ah, eu fico naquela. Eu espero por Deus, né? Eu fico na minha (...). Alguma coisa ruim, se tiver que acontecer, vai acontecer em qualquer outro lugar. Mas aí a gente, a gente pede, ora muito a Deus para não acontecer nada, porque, Deus me perdoe, eu com o bebê não tem como, né?
Observa-se a atitude fatalista na fala da entrevistada, sustentada na ideia de que o que tem que acontecer, simplesmente acontece, e não há como escapar do fato. Tal atitude fatalista, aliada à religiosidade, evidencia a ausência de criticidade do risco de acidente como precariedade do trabalho. Borsoi, ao estudar sobre acidente fatal na construção civil, afirma:

Se Deus protege e pune, se Deus tem o poder sobre a vida e sobre a morte, tudo o que ocorre aos homens está de antemão determinado por ele. Desse modo, a religião acaba fornecendo uma munição importante à atitude fatalista que, por sua vez, facilita a aceitação de determinadas condições de desigualdade social e exploração (2005, p.25)

Apenas um informante falou sobre o processo de superação e de enfrentamento em relação à perda vivenciada pela família, do qual não se exclui a questão financeira:

Ah, a família tirou forças, assim, juntos, unidos, né? Com os outros que ficou. Ele (pai da vítima) mesmo ficou nos netos (sobrinhos do acidentado), que hoje esses dois netos pra ele é tudo. $E$, assim, é entre a família mesmo, porque, coisa assim... Amigos dele também vinha, conversava, dava aquela força, né? (...) a ajuda financeira mesmo só foi a indenização que foi combinado entre eles (cunhada).

O empregador expressou também as dificuldades emocionais e de ordem prática vivenciadas por ele, pois teve que se defender e provar sua inocência, mesmo fazendo tudo para prevenir acidentes. Relatou que o lado psicossocial do empresário não é levado em conta, pois, no mesmo período em que o acidente de trabalho ocorreu, estava passando por problemas de ordem pessoal, que preferiu não revelar. É importante ressaltar que não é possível estabelecer parâmetros de comparação entre o impacto do acidente de trabalho para a família e os problemas pessoais enfrentados pelo empregador, pois os fenômenos situam-se em esferas distintas: público/profissional x privado/ pessoal. Por outro lado, sabe-se que o acidente 
traz implicações psicossociais não só para a família mas também para o empregador: "Você acha que é fácil ser acordado três da manhã com funcionário seu morto na empresa?" (empregador).

\section{Mudanças na dinâmica familiar}

Em relação às consequências e mudanças após o acidente, os familiares referem-se à dificuldade em arcar com as despesas, já que a vítima era responsável pelo orçamento da casa:

(...) Foi triste pra eles. Era um menino que fazia tudo em casa, né? Pagava aluguel, água, energia, tudo. Era tudo por conta dele, né? Ainda bem que ainda conseguiu comprar uma casinha, né? Aí eles não pagam aluguel, né? (...). E era mais era ele mesmo que cobria as necessidades deles (cunhada).

Segundo os depoimentos dos membros da família, a vítima havia feito a promessa de comprar uma casa para eles, o que foi possibilitado pela indenização após a sua morte. A aquisição da casa pelos pais alterou a dinâmica familiar, pois os demais filhos também construíram suas casas próprias no terreno atrás da casa:

Ele sempre falava, falava com ele: 'Um dia eu vou ter uma casinha pra vocês. Vocês não vão morar de aluguel mais'. Então, às vezes, eles lembra disso aqui e fala: 'Ah, ele morreu pra deixar isso aqui pra gente'. Aí, eu sempre falo com ele: 'Não é isso. Aconteceu. Aí vocês compraram isso aqui, vocês agradeçam muito a Deus que ele ainda deixou isso aqui pra vocês". (...) nós também pagávamos aluguel e agora a gente tem a casinha dos fundos (cunhada).

O pai contou que não está recebendo o benefício do INSS, porque havia entendido que a empresa se responsabilizaria não só pela indenização mas também pela pensão. Ao reconhecer seus direitos, questiona esse fato:

(...) vou lá no INSS (...) pra ver a pensão, eu vou fazer o quê, né? Vai ter que dar lucro pra nós, estamos precisando do dinheiro, porqueele tinha o direito da pensão (...) porque é direito (pai).
O relato do pai contrasta com a fala do empregador, que informou que apoiou a família para conseguir esse benefício, mas não obtiveram sucesso, já que os pais da vítima não conseguiram comprovar que o filho era o provedor da família. A comunidade também reconhece tais direitos e reforça essa ideia de legitimidade desse benefício: "Tem um monte que recebe a pensão dos filhos que morreu, um monte me orientou que recebe a pensão, né? Por que que eu não recebo? Eu tenho direito de receber também" (pai).

O empregador relatou que fez acordo com a família, pagando tudo o que pudesse ser requerido posteriormente na Justiça, mas, depois de dois anos, veio o sindicato e atrapalhou tudo, pois instruiu a família a entrar com novos recursos; no entanto, o pedido de pensão teve que ser retirado, senão a família iria ter que devolver todos os gastos despendidos pela empresa.

Os depoimentos obtidos em entrevistas apontam uma contradição existente entre a percepção da família e a do empregador sobre o acidente de trabalho. No decorrer das entrevistas, tais percepções associavamse principalmente às condições de trabalho da vítima, às consequências psicossociais do acidente e às mudanças na dinâmica familiar, incluindo questões financeiras.

\section{Redução fenomenológica}

A descrição das entrevistas por meio de eixos temáticos apresentados na descrição (condições de trabalho da vítima, consequências psicossociais do acidente e mudanças na dinâmica familiar) são categorias iniciais, cuja redução aponta uma estrutura mais abrangente, que desvela um paradoxo importante sobre o fenômeno do acidente de trabalho. A descrição e a explicitação dos conflitos presentes nas experiências vivenciadas por esses indivíduos constituem o fio condutor para analisar esse fenômeno. 
Os depoimentos destacam um paradoxo sobre a percepção da família e a do empregador sobre o acidente. A repercussão do acidente para a família fundamenta-se na importância social do trabalho e no lugar de provedor ocupado pelo trabalhador na família. A preocupação dos familiares gira não só em torno da sobrevivência - ganhos financeiros obtidos com a indenização e dificuldades em arcar com as despesas da casa - mas também da defesa do filho, para que ele não seja considerado culpado pelo acidente.

Para o empregador, a repercussão do acidente associa-se à defesa da empresa quanto à morte no trabalho, pautada no fato de investir em segurança para prevenir acidentes. O empregador apresenta ideia subjacente de culpabilização do trabalhador, que é explicitada ao relatar que o técnico em segurança do trabalho não avisa o horário em que atuará para "pegar o funcionário no flagra". Ao mesmo tempo em que o empregador explicita o investimento em segurança para se resguardar quanto à ocorrência do acidente, só assinou a carteira de trabalho da vítima após o acidente, conforme afirma a família.

As informações sobre o acidente não são claras. Tanto os familiares quanto o empregador não sabem (ou não revelam) como aconteceu e não têm informações sobre sua causa. Esse ciclo sobre a investigação do acidente, no qual a empresa não informa os fatos com clareza e a família não busca o esclarecimento, contribui para reforçar a naturalização do acidente de trabalho, da morte e da culpabilização do trabalhador.

Outro paradoxo evidenciado refere-se ao trabalho padronizado e ao que é realizado de fato. O empregador revela que o trabalhador sabia das normas para manusear as chapas e as negligenciou. Já o sindicato afirma que o cumprimento da norma não é possível de ser seguido na realização de tal atividade. A família suspeita que pode ter havido falhas nos equipamentos de segurança.
As contradições do acidente de trabalho desveladas na descrição do fenômeno podem ser compreendidas também à luz de estudos relacionados com a produção social do acidente de trabalho, com a saúde do trabalhador e a psicodinâmica do trabalho, como mostra a interpretação fenomenológica.

\section{Interpretação fenomenológica}

O último passo da análise fenomenológica é interpretar os elementos da descrição e da redução fenomenológica. Cada participante descreveu suas percepções e reações ao acidente de trabalho e, a partir desses relatos, foram selecionados os elementos essenciais que explicam a consciência e a experiência do fenômeno. A literatura a respeito da saúde do trabalhador propõe que a análise dessa temática conjugue elementos referentes à organização e às relações sociais no trabalho com as vivências subjetivas dos implicados no contexto sociohistórico do trabalho. Aponta-se a importância que a organização do trabalho assume, bem como são ressaltadas as questões psicossociais relacionadas para a análise do acidente de trabalho fatal.

Nos relatos apresentados, verificam-se percepções distintas dos familiares e do empregador em relação à organização das condições de trabalho. Para o empresário, o trabalho é regido por normas, pela preocupação com o cumprimento da legislação e pelo cuidado com a segurança e a saúde do funcionário. Já para a família, a empresa não levou em conta questões concretas e práticas do trabalho, como o pouco tempo de experiência do trabalhador.

O empresário entrevistado enfatiza a prevenção e a segurança do trabalho realizada pela empresa, o que sugere que cumpriu sua parte formal, como se a prevenção a isentasse da responsabilidade com aspectos invisíveis do trabalho, como a falta de experiência e o pouco treinamento da vítima. Na ótica dos familiares, 
houve negligência por parte da empresa, sendo mencionado que a inexperiência foi um dos fatores responsáveis pelo acidente. Moulin, Reis e Wenichi (2001) retratam a percepção dos trabalhadores sobre segurança no que se refere ao uso de equipamento de proteção individual (EPI). Segundo esse estudo, para os trabalhadores, muitas vezes, seguir os procedimentos impostos pela segurança interfere de forma negativa na realização do trabalho:

Muitos dos EPIs causam desconforto aos trabalhadores; aqui o zelo pelo trabalho fala mais alto do que a própria proteção à saúde. Com todos esses equipamentos, tenho que trabalhar mais devagar, não enxergo direito, não respiro direito. Será que o patrão está disposto a diminuir o ritmo de produção? Em segundo lugar, os trabalhadores, embora nem sempre enunciem, têm clareza dos limites da proteção oferecida pelos EPIs (Moulin et al., 2001, p. 62)

De acordo com Dejours e Jayet (2009, p. 101), a organização do trabalho implica, por um lado, o modo operatório prescrito (conteúdo das tarefas) e, por outro, a divisão das tarefas (repartição das responsabilidades, hierarquia, comando e controle), mas salienta que esta “(...) não é só técnica nem regulamentária, ela é também objeto de um complexo jogo de relações sociais de trabalho", constitui-se, portanto, de uma dimensão que transcende os aspectos técnicos, pois é social e construída nas relações intersubjetivas.

A partir dessa ótica, deve-se considerar uma distinção entre trabalho prescrito realizado e trabalho real. O primeiro diz respeito ao aspecto normativo da tarefa a ser cumprida, cujas diretrizes geralmente são dadas considerando uma situação-modelo, que negligencia as variabilidades das situações de trabalho. O trabalho a ser realizado demanda do sujeito respostas a uma realidade bem mais complexa do que aquela prevista pela prescrição. $O$ trabalho impõe-se aos trabalhadores por meio do imprevisto, do inesperado, independentemente da qualidade da concepção e da precisão dos procedimentos. O trabalho, ao escapar da prescrição, assume o sentido de trabalho real.

As atividades atribuídas aos trabalhadores implicam reajustamentos dos modos de realizálas em uma situação real, pois sempre restará uma parcela de responsabilidade que retornará aos trabalhadores. Dessa forma, o engajamento subjetivo é convocado mediante procedimentos e decisões que muitas vezes se antecipam à consciência dos atos práticos (Dejours et al., 2009).

Podemos inferir que o acidente de trabalho não se restringe à negligência, mas reporta-se a uma forma de apropriação do trabalho realizado pela vítima de acidente fatal, apresentado neste estudo. O trabalho prescrito, como defendido pelo empregador, nem sempre é possível. O conflito é inevitável entre as diretrizes normativas da empresa e o trabalho - real. Em consequência, observa-se o conflito de percepções entre o empregador, os familiares da vítima e o sindicato.

Nesse contexto, a saúde no trabalho está na possibilidade de os sujeitos negociarem com a organização prescrita do trabalho, traduzindo no enfrentamento e desenvolvendo um trabalho em seu domínio real, ou seja, na possibilidade de criar. É a partir do desafio colocado pelo trabalho real que o sujeito acrescenta algo de inédito a ele, algo de sua autoria, por intermédio de sua ação singular sobre a tarefa e sobre as rotinas já dadas pela organização prescrita (Dejours et al., 2009).

É importante salientar que a inserção do sujeito entre o trabalho prescrito e o real é sempre conflitiva, e não se dá fora do contexto das relações sociais no trabalho. É nesse ponto que se evidencia um elemento fundamental para a análise dos relatos dos entrevistados. 
A aceitação de um trabalho nas condições citadas (sem carteira assinada) pode estar associada à instabilidade do mercado de trabalho e à fragilidade das relações que se estabelecem a partir dele (Antunes \& Alves, 2004; Seligmann-Silva, 1994), que podem explicar também o fato de o colega da vítima não revelar detalhes do acidente por receio de comprometer seu trabalho, na percepção da família.

Embora o fenômeno estudado tenha se apresentado como paradoxal no que tange à percepção desse fato para os familiares e para o empregador da vítima, a naturalização do acidente emerge como ponto comum tanto nas falas quanto no que não foi dito pelos participantes. O empregador baseia sua defesa nas ações que empreendeu em prol da segurança e da legislação, logo, para ele, o que aconteceu foi uma fatalidade causada pelo descuido do trabalhador. O pai da vítima, por sua vez, relata, em muitos momentos da entrevista, que não há mais o que possa ser feito em relação à morte, e que ele deve se conformar.

A naturalização e a culpabilização dos trabalhadores em relação aos acidentes de trabalho também são interesse de estudo em vários setores, como na indústria (Freitas, 2001; Oliveira, 2007), na construção civil (Mangas et al., 2008; Oliveira \& Iriart, 2008) e na siderurgia (Moraes \& Moulin, 2010). Nos estudos realizados por Moulin (2003, 2006, 2007) no setor de rochas ornamentais, é abordada a naturalização dos riscos e da morte para o grupo de trabalhadores pesquisados e também para toda a comunidade (sul do Estado do Espírito Santo), na qual o trabalho que, ao mesmo tempo ordena e dá sentido às relações sociais, traz agravos à saúde e pode levar à morte. Faz parte desse processo de naturalização a culpabilização dos trabalhadores e a minimização dos riscos, este último como importante mecanismo de defesa coletivo para suportar o trabalho penoso e perigoso.

\section{Considerações finais}

As contradições entre o que foi dito pelos familiares e pelo empresário do setor revelam o conflito entre o capital e o trabalho, principalmente no cenário neoliberal, em que há uma acentuada precarização do trabalho. As condições de trabalho inadequadas, por vezes, são aceitas pelas vítimas e familiares, o que pode estar relacionado com a resignação dos envolvidos.

É importante pensar nas formas de ampliar a ação coletiva de trabalhadores sobre o ambiente de trabalho real e sobre sua própria atividade. Para tanto, deve-se refletir, no campo da Psicologia do trabalho, sobre estratégias coletivas, como pressionar o poder público por medidas protetivas em frente aos riscos relacionados com a organização do trabalho no setor de mármore e granito.

O estudo realizado, longe de refletir questões no plano individual, em que cada trabalhador deveria buscar soluções individualizadas, ao contrário, procurou refletir sobre questões individuais que são de ordem coletiva. A reflexão sobre as percepções do acidente de trabalho fatal constitui uma possibilidade de compreender melhor esse fenômeno. Embora não pretenda generalizar, o trabalho apresenta uma interpretação possível sobre o mundo do trabalho, cujos conflitos e paradoxos não estão dissociados da sociedade e da cultura em que se inserem.

A abordagem fenomenológico-semiótica visa a apresentar as vivências dos sujeitos da perspectiva daqueles implicados em um processo de trabalho, que reflete um campo de tensões de interesses. Trata-se de uma possibilidade de dar voz aos trabalhadores, para que recriem formas de relações com o mundo do trabalho. 


\section{Ana Beatryce Tedesco Moraes}

Mestre em Psicologia Social pela Universidade Federal do Espírito Santo, Vitória - ES - Brasil.

E-mail: anabeatryce@hotmail.com

\section{Cláudia Balestreiro Pepino}

Doutoranda em Psicologia Social pela Universidade Federal do Espírito Santo, Vitória - ES - Brasil.

E-mail: cbp@uvv.br

\section{Maria das Graças Barbosa Moulin}

Doutora e professora do Departamento de Psicologia Social e do Desenvolvimento e professora colaboradora do

Programa de Pós-Graduação em Psicologia da Universidade Federal do Espírito Santo, Vitória - ES - Brasil.

E-mail: mgbmoulin@gmail.com

\section{Mariane Lima de Souza}

Doutora e professora do Departamento de Psicologia Social e do Desenvolvimento e do Programa de Pós-

Graduação em Psicologia da Universidade Federal do Espírito Santo, Vitória - ES - Brasil.

E-mail: limadesouza@gmail.com

Endereço para envio de correspondência:

Dr. Guilherme Serrano, 26, ap. 1204, Santa Luiza, Vitória, ES, CEP: 29045-410

Recebido 18/03/201, Aprovado 31/07/2012. 


\section{Referências}

Antunes, R., \& Alves, G. (2004). As mutações no mundo do trabalho na era da mundialização do capital. Educação e Sociedade, 25(87), 335-351.

Borsoi, I. C. (2005). Acidente de trabalho, morte e fatalismo. Psicologia \& Sociedade, 17, 17-28.

Dejours, C., \& Jayet, C. (2009). Psicopatologia do trabalho e organização real do trabalho em uma indústria de processo: metodologia aplicada a um caso. In C. Dejours, E. Abdoucheli \& C. Jayet, (Org.). Psicodinâmica do trabalho: contribuições da escola dejouriana à análise da relação prazer, sofrimento e trabalho (pp. 67-118, 10a reimpr.) São Paulo: Atlas.

Dejours, C., Abdoucheli, E., \& Jayet, C. (Org.). (2009). Psicodinâmica do trabalho: contribuições da escola dejouriana à análise da relação prazer, sofrimento e trabalho (10a reimpr.). São Paulo: Atlas.

Freitas, C. M. (2001). A análise de acidente de trabalho em indústrias tendo como referência a organização do trabalho. In L. H. Borges, M. G. B. Moulin \& M. D. Araújo (Orgs.). Organização do trabalho e saúde: múltiplas relações (pp. 87108). Vitória, ES: Editora EDUFES/CCHN.

Gomes, W. B. (Org.). (1998). Fenomenologia e pesquisa em psicologia. Porto Alegre: Editora da Universidade Federal do Rio Grande do Sul.

Jardim, S. R. (2001). Trabalho e doença mental. In L. H. Borges, M. G. B. Moulin \& M. D. Araújo (Orgs.). Organização do trabalho e saúde: múltiplas relações (pp. 137-156). Vitória, ES: Editora EDUFES/CCNH.

Lanigan, R. L. (1997). Capta versus data: método e evidência em comunicologia. Psicologia: Reflexão e Crítica, 10, 17-45.

Magalhães, M. O., Lassance, M. C., \& Gomes, W. B. (1998). Escolha vocacional em adolescentes. In W. B. Gomes, Fenomenologia e pesquisa em psicologia (pp. 161-195). Porto Alegre: Editora da Universidade Federal do Rio Grande do Sul.

Mangas, R. M. N., Minayo-Gomez, C., \& Thedim-Costa, S. M. F. (2008). Acidentes de trabalho fatais e desproteção social na indústria da construção civil do Rio de Janeiro. Revista Brasileira de Saúde Ocupacional, 33(118), 48-55.

Matsuo, M. (2002). Acidentado do trabalho: reabilitação ou exclusão? São Paulo: Fundacentro.

Minayo, M. C. S. (Org.). (2007). Pesquisa social: teoria, método e criatividade (26a ed.). Petrópolis, RJ: Vozes.

Moraes, A. B. T., \& Moulin, M. G. B. (2010). Representações sociais de acidente de trabalho para trabalhadores de empresa siderúrgica. Trabalho \& Educação, 19(1), 81-94.

Moulin, M. G. B., Reis, C. T., \& Wenichi, G. H. (2001). Homens de pedra? Pesquisando o processo de trabalho e saúde na extração e no beneficiamento do mármore - relato de uma experiência. Cadernos de Psicologia Social do Trabalho, 3-4, 47-63.

Moulin, M. G. B. (2006). O lado não polido do mármore e granito: a produção social dos acidentes de trabalho e suas conseqüências no setor de rochas ornamentais no sul do Estado do Espírito Santo. Tese de doutorado. Fundação Oswaldo Cruz, Escola Nacional de Saúde Pública Sérgio Arouca, Rio de Janeiro.

Moulin, M. G. B. (2007). De heróis e de mártires: visões de mundo e acidentes de trabalho no setor de rochas ornamentais. Cadernos de Psicologia Social do Trabalho, 10(1), 37-53.

Moulin, M. G. B. (2008). Desafios para a saúde do trabalhador: vida e morte nas pedreiras de mármore. In E. M. Rosa, L. Souza \& L. Z. Avellar (Orgs.). Psicologia social: temas em debate (pp. 153-165). Vitória, ES: UFES/ABRAPSO.

Moulin, M. G. B., \& Raizem, M. H. (2010). Levantamento de acidentes de trabalho fatais ocorridos em 2008 no setor de rochas ornamentais no Estado do Espírito Santo. Trabalho apresentado na Jornada de Iniciação Científica 2009/2010, do Programa Institucional de Iniciação Científica da Universidade Federal do Espírito Santo, Vitória, ES.

Nardi, H. C. O. (1998). Ethos masculino e o adoecimento relacionado ao trabalho. In L. F. D. Duarte, \& O. F. Leal (Orgs.). Doença, sofrimento, perturbação: perspectivas etnográficas (pp. 95-104). Rio de Janeiro: Editora Fiocruz.

Oliveira, F. (2007). A persistência da noção de ato inseguro e a construção da culpa: os discursos sobre os acidentes de trabalho em uma indústria metalúrgica. Revista Brasileira de Saúde Ocupacional, 32(115), 19-27.

Oliveira, R. P., \& Iriart, J. A. B. (2008). Representações do trabalho entre trabalhadores informais da construção civil. Psicologia em Estudo, 13(3), 437-445.

Seligmann-Silva, E. (1994). Desgaste mental no trabalho dominado. Rio de Janeiro: Editora UFRJ; Cortez Editora.

Seligmann-Silva, E. (1990). Sociabilidade, trabalho e loucura: repercussões das condições de trabalho sobre a vida familiar. Jornal Brasileiro de Psiquiatria, 39, 235-275.

Wünsch-Filho, V. (1999). Reestruturação produtiva e acidentes de trabalho no Brasil: estrutura e tendências. Cadernos de Saúde Pública, 15(1), 41-51. 